\title{
JEAN VON ROESGEN: UN PINTOR ACTUAL QUE TRIUNFA CON SU DALTONISMO
}

\author{
MIR FULLANA $F^{1}$
}

Jean von Roesgen nació en Luxemburgo en el año 1963 y es el quinto de seis hermanos de los cuales tres padecen daltonismo. Su biografía demuestra un carácter bohemio con un alto componente místico. Cuando acabó el bachillerato comenzó estudios superiores de matemáticas que abandonó un año después. Después de diversos trabajos, en el año 1984 permaneció tres meses en un monasterio benedictino de los Pirineos, regresando a pie e ini-

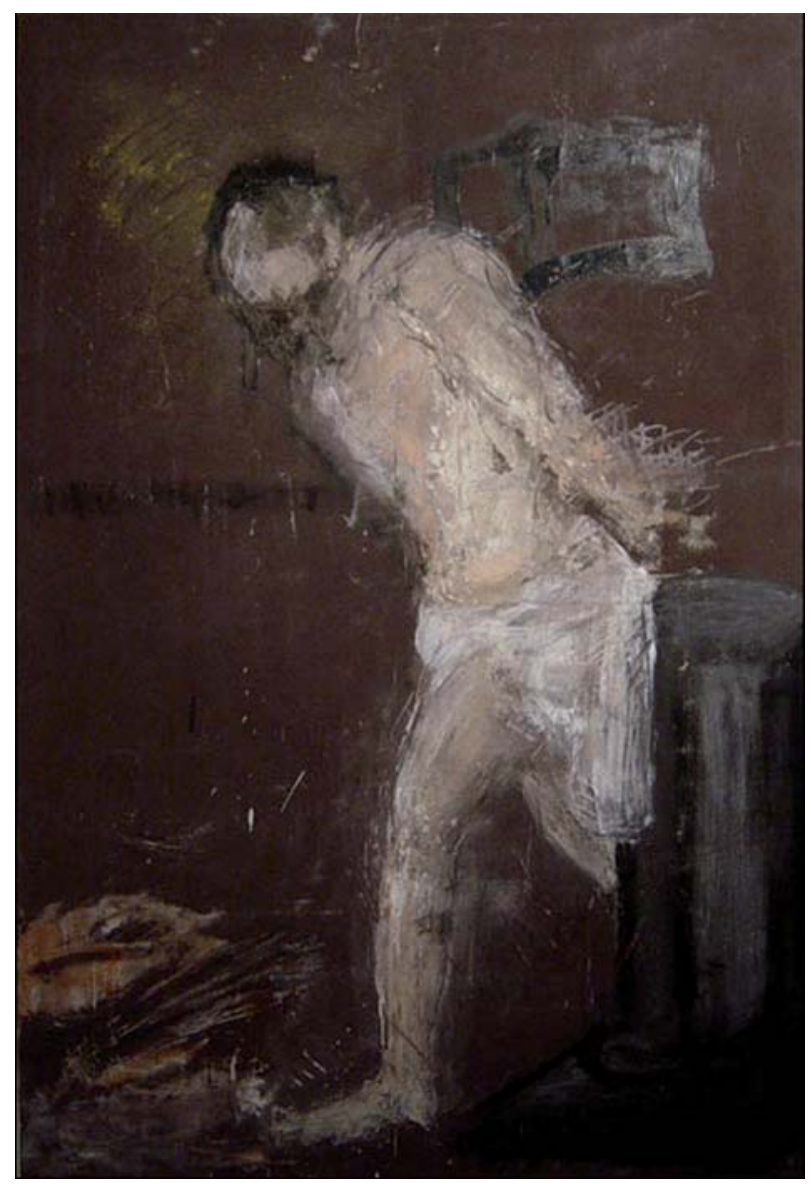

Cristo (1998). ciando estudios de teología en la facultad católica de Trèves (1986-1987) y después en Lyon. En el año 1989 presentó la tesis sobre la demonología de San Antonio incluyendo un estudio de sus interpretaciones iconográficas.

A partir del año 1990 estudió Bellas Artes en l'École Nationale des Beaux-Arts de Lyon y durante los años 1993 y 1994 en la Academia de Bellas Artes de Dresde, diplomándose en Lyon en 1996. Al año siguiente se instaló en la región francesa de Lot donde sigue pintando y cultivando su huerto.

En todas sus pinturas se puede observar la utilización de los amarillos, sepias y azules evitando los rojos y verdes, que da a sus obras el monocromatismo típico de los daltónicos.

A pesar de su importante anomalía para un artista plástico, Jean von Roesgen constituye un ejemplo a seguir para todos aquellos que no se dan por vencidos.

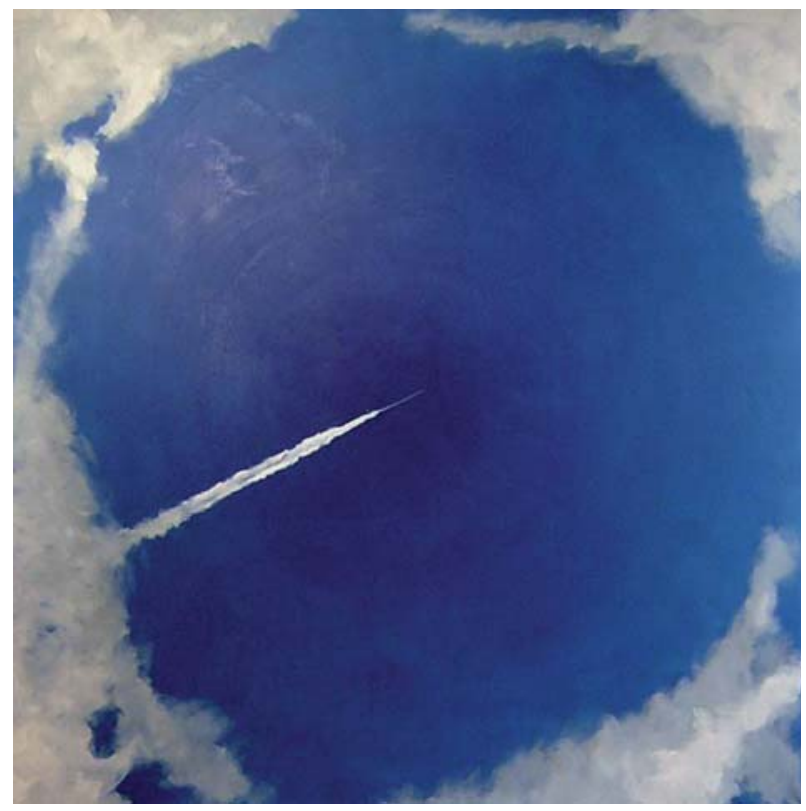

Cielo.

\footnotetext{
1 Oftalmólogo.

E-mail: Fmir@mutuabalear.es
} 
Cole y Nathan (1) estudiaron el caso de un pintor aficionado que padecía una extrema deuteranomalía. Su paleta se limitaba a los azules, amarillos y naranjas, adoptando estrategias para no confundir los colores. Evitaba los amarillo-verdosos de los que no estaba seguro. A pesar de las dificultades era capaz de crear atractivas pinturas. Sus primeras obras eran monocromáticas pero más adelante fue capaz de crear intensos efectos cromáticos si bien con una paleta limitada.
La conclusión es que un defecto en la visión de los colores constituye un hándicap para las actividades de un artista pintor en las que la cromaticidad se necesita de forma especial... pero que no constituye una barrera infranqueable.

\section{BIBLIOGRAFÍA}

1. Cole BL, Nathan J. An artist with extreme deuteranomaly. Clin Exp Optom 2002; 85: 3000-3005. 